aminoaciduria calcitonin cyclic nucleotides dietary hypocalcemia parathyroid hormone phosphaturia vitamin $\mathrm{D}$ deficiency

\title{
Effect of Calciotropic Hormones and Cyclic Nucleotides on Aminoaciduria and Phosphaturia
}

\author{
RODERICK R. McINNES ${ }^{(58)}$ AND CHARLES R. SCRIVER \\ The Department of Biology, Faculty of Science, and Department of Pediatrics, Faculty of Medicine, McGill University, \\ Montreal, Quebec, Canada
}

\section{Summary}

Parathyroid extract (PTE), dibutyrylcyclic AMP (dbcAMP), adenosine cyclic $3^{\prime}: 5^{\prime}$-monophosphate (cAMP), calcitonin (CT), and calcium chloride were infused separately into anesthetized, sham-operated, or TPTX vitamin D-fed adult rats to examine the effect of these calciotropic agents on fractional excretion (FE) of $\alpha$-aminoisobutyric acid (AIB), and phosphate anion $\left(P_{i}\right)$. AIB is a nonmetabolizable amino acid.

Inulin clearance, $\mathrm{FE}_{\mathrm{AIB}}$, and $\mathrm{FE}_{\mathrm{P}_{1}}$ were stable in the intact (n $=10)$ and TPTX rat $(n=10)$. TPTX decreased FE AIB, $_{\text {, and }}$ FE $_{P_{i}}$ significantly $(P<0.001$ for both). PTE and dbcAMP both increased $F E_{A I B}$ in the intact rat $(P<0.001)$; failure to obtain this response in the TPTX animal was a key finding. PTE and dbcAMP increased $F E_{P_{1}}(P<0.001)$ in both the intact and TPTX animal. CT was the only agent (versus PTE, dbcAMP, adenosine cyclic 3': 5'-monophosphate, and $\left.\mathrm{CaCl}_{2}\right)$ to increase $\mathrm{FE}_{\mathrm{AIB}}(P<0.001)$ in the TPTX rat; furthermore, it was the only agent that did not increase FE $_{\mathbf{P}_{i}}$ in the TPTX rat although it had hypocalcemic and hypophosphatemic effects. Changes in inulin clearance or plasma concentration of AIB, following infusion of calciotropic agents, do not explain the unique responses in $\mathrm{FE}_{\mathrm{AIB}}$ in the TPTX rat.

Our findings suggest that hyperaminoaciduria induced by parathyroid hormone and cyclic nucleotide in the intact animal may be mediated by CT. Hyperphosphaturia is not a necessary response to small-dose $(25$ milliunits $/ \mathrm{kg} \cdot \mathrm{hr})$ infusions of $\mathrm{CT}$.

\section{Speculation}

Intracellular calcium in renal epithelium may be the final determinant of hyperaminoaciduria in hyperparathyroidism.

Net renal tubular reabsorption is impaired in man in the presence of vitamin D or primary calcium deficiency and in primary hyperparathyroidism (37). The tubular dysfunction includes excessive phosphaturia and aminoaciduria $(17,28,33)$, bicarbonate loss $(38,39)$, and increased excretion of other solutes normally reabsorbed by the proximal tubule (12).

The origin of the tubulopathy is unknown. Alterations in renal hemodynamics $(37,38)$ or permeability characteristics of the proximal tubule $(30,31)$ related to an excess of PTH $(1,26)$ or cAMP $(51,52)$ may be responsible. However, excess PTH does not uniformly evince impaired reabsorption of solute. For example, there is no hyperaminoaciduria in two-thirds of patients with primary hyperparathyroidism (14). Muldowney et al. (39) noted no increase in amino acid excretion after giving PTE to normal subjects, and of four subjects with endogenous hyperparathyroidism or infused with PTH, only two had depressed amino acid reabsorption (48).

The above-mentioned observations suggest that increased PTH secretion per se is not enough to cause hyperaminoaciduria and that additional factors must be involved. We have examined the problem of PTH-related hyperaminoaciduria further by examining the effects of infused calciotropic hormones and cyclic nucleotides on tubular reabsorption of phosphate and of AIB a nonmetabolizable amino acid. Normocalcemic vitamin D-replete rats, either intact or acutely TPTX, were used in these studies.

\section{MATERIALS AND METHODS}

Female, Long-Evans hooded rats (190 to $220 \mathrm{~g}$ ) were obtained from Canadian Breeding Farms, St. Eustache, Quebec, Canada and anesthetized with Inactin $(100 \mathrm{mg} / \mathrm{kg}$ ) (Henley \& Co., N. Y.). Following dissection of the neck, the thyroid, and parathyroid glands were either left intact (sham operated) or removed (TPTX) by electric cautery.

Renal clearance studies began 4 to $6 \mathrm{hr}$ following surgery when endogenous PTH and CT had been cleared from the circulation through at least five half-lives. An external jugular vein (for infusions) and a femoral artery (for blood sampling) were catheterized with polyethylene tubing, and the bladder was tied off to reduce dead space as described previously (36). The animals were infused with a solution containing $60 \mathrm{mM} \mathrm{NaCl}, 2.3 \mathrm{mM} \mathrm{KCl}, 1.3$ $\mathrm{g} / \mathrm{dl}$ inulin, and $400 \mu \mathrm{Ci} /$ liter inulin-methoxy $\left({ }^{3} \mathrm{H}\right]$ methoxy, 50 to $150 \mu \mathrm{Ci} / \mathrm{g}$ ) at $16 \mathrm{ml} / \mathrm{kg} \cdot \mathrm{hr}$, to achieve a steady-state of inulin clearance and urine flow following which, seven or eight consecutive clearance periods of 30 to $35 \mathrm{~min}$ each were obtained. Near the midpoint of the clearance periods, blood samples (80 to 130 $\mu$ l each) were collected into heparinized capillary tubes. Inulin and AIB in plasma and hematocrit were measured in all periods; plasma phosphate was measured in periods $1,3,5$, and 7 . Urine inulin, phosphate, AIB, and urine volume were measured, and the animal was weighed in each clearance period.

\section{INFUSION OF CALCIUM. CALCIOTROPIC HORMONES. AND CYCLIC NUCLEOTIDES}

Infusions were performed with a Sage Model-355 Infusion Pump (Orion Res. Inc., Cambridge, MA). The syringe containing the test substance was inserted into the polyethylene tubing delivering the sustaining solution of electrolytes and inulin. Experimental infusions included: (1) calcium chloride, $0.66 \mathrm{mmoles} / \mathrm{g}$. hr; (2) PTE, (100 USP units/ml; Lilly, Para-thor-mone) 40 units/ $\mathrm{g} \cdot \mathrm{hr}$; (3) purified porcine calcitonin ( $90 \mathrm{MRC}$ units/mg, generously provided by Dr. Claude Arnaud), 25 or 500 munits $/ g$. hr; (4) dbcAMP (Sigma Chemical Co., St. Louis, MO), $15 \mathrm{mg} / \mathrm{g} \cdot \mathrm{hr}$; (5) cAMP (Sigma Chemical Co.), $5 \mathrm{mg} / \mathrm{kg} \cdot \mathrm{hr}$. Nucleotides were dissolved in the infusion mixture no earlier than $30 \mathrm{~min}$ before their use. PTE was infused undiluted to maintain its stability. CT was dissolved in a solution containing $0.9 \% \mathrm{NaCl}$ solution and acetic acid $(0.01 \mathrm{mM})$ in the ratio $1: 1$ and human albumin $(4 \mathrm{mg} /$ $\mathrm{ml}$ ). Less than $200 \mu \mathrm{l}$ of this particular solution was infused per animal; vehicle alone was infused in the control periods. 


\section{RENAL CLEARANCE PROTOCOL}

Three control clearance periods were obtained on each rat followed by four experimental clearance periods. This allowed each rat to serve as its own control, an approach necessitated by the important (3-fold) interanimal variation in $\mathrm{FE}_{\mathrm{AIB}}(36)$.

\section{ANALYTICAL METHODS}

Established methods (see Ref. 36 for details) were used for liquid-scintillation counting, verification of the radiochemical purity of $\left[1-{ }^{14} \mathrm{C}\right] \mathrm{AIB}$ (New England Nuclear, Boston, MA) and inulin $\left[{ }^{3} \mathrm{H}\right]$ methoxy (New England Nuclear) and the measurement of phosphate in plasma and urine.

\section{STATISTICAL METHODS}

Analysis of variance (49) was performed on the data for renal clearance, FE, and plasma concentrations of AIB and $P_{i}$. The rat, in our preparation, has excellent intraindividual stability of $F_{A I B}, F E_{P}, G F R$, and plasma AIB under control conditions (36). Data in this report are presented as the mean \pm S.E. of pooled interindividual differences for the means of the control (first three) clearance periods and for the difference in each experimental clearance period from the control mean to accommodate interindividual variation and permit pooled data to be analyzed from all rats studied under a specific protocol.

\section{RESULTS}

\section{CONTROL DATA}

$F E_{A I H}, F E_{P}$, and GFR were stable under control conditions (Fig. 1). $\mathrm{FE}_{\mathrm{AIB}}$ and $\mathrm{FE}_{\mathrm{P}}$ decreased following TPTX $(P<0.001)$, the change from control being greater for phosphate than for AIB. GFR was not altered by TPTX.

\section{RESPONSE TO INFUSION OF PTE OR DBCAMP}

Intact Animal. PTE given to the intact rat increased $\mathrm{FE}_{\mathrm{AIB}}$ significantly $\triangle F E_{A I B},+0.061 \pm 0.016$, mean $\pm S$.E. after $60 \mathrm{~min}$;
$P<0.001$ ) (Fig. 2). The renal response to PTE is mediated, at least partly, by the generation of cAMP (11). Accordingly, the effect of its analog dbcAMP was examined. $F_{\text {AIB }}$ was increased significantly by dbcAMP in the intact rat $\left(\triangle \mathrm{FE}_{\mathrm{AlB}},+0.043 \pm 0.006\right.$ after $60 \mathrm{~min} ; P<0.001$ ) (Fig. 2).

FE $E_{P}$ increased significantly $(P<0.001)$ when either PTE or dbcAMP was given to the intact animal (Fig. 2).

PTE and dbcAMP had opposing effects on GFR on the intact sham-operated animal (Fig. 2), despite their similar effects on $\mathrm{FE}_{\mathrm{AIB}}$ and $\mathrm{FE}_{\mathrm{P}}$. PTE produced a significant fall in GFR ( $\triangle \mathrm{GFR}$ $-0.33 \pm 0.06$ after $60 \mathrm{~min} ; P<0.001)$ whereas dbcAMP increased it slightly $(P<0.05$, first 30 min period only).

TPTX Animal. Neither PTE nor dbcAMP altered $\mathrm{FE}_{\mathrm{AIB}}$ in the TPTX rat (Fig. 3). This is a key finding in the present study. Both agents increased FE $F_{P}$, significantly in the TPTX rat $(P<0.001)$ (Fig. 3).

The time course of the phosphaturic response to PTE was slower in the TPTX animals when compared to that of the intact rat (difference between $\Delta F E_{P}$ in the first treatment period of the two groups; $P<0.001$ ), and the phosphaturia provoked by dbcAMP was greater in TPTX rats $(P<0.001)$ than in the intact animal given the same dose of nucleotide (namely, Fig. 3 versus Fig. 2). The greater filtered load of $P_{i}$ in TPTX animals may explain the greater $F E_{P}$ in the latter following dbcAMP.

GFR was decreased by PTE ( $\triangle$ GFR, $-0.13 \pm 0.05$ after $30 \mathrm{~min}$; $P<0.001)$ and increased by dbcAMP ( $\triangle$ GFR, $+0.13 \pm$ within 30 min, $P<0.005$ ) (Fig. 3); these responses in GFR to the two agents are similar to those seen in the intact rat.

\section{INFUSION OF CAMP AND CALCIUM: TPTX RAT}

cAMP reduced $F_{\text {AIB }}$ in the TPTX rat (Fig. 3) $\left(\triangle F_{\text {AIB, }},-0.032\right.$ \pm 0.005 after $60 \mathrm{~min} ; P<0.001$ ), increased $F E_{P}$, significantly $\left(\triangle F_{P_{1}},+0.13 \pm 0.001\right.$ after $\left.60 \mathrm{~min} ; P<0.001\right)$, and reduced $G F R$ ( $\triangle \mathrm{GFR},-0.16 \pm 0.05 ; P<0.005$ ).

The response to calcium (infused as $\mathrm{CaCl}_{2}$ ) was similar to that following cAMP in the TPTX rat (Fig. 3). FE $E_{A I B}$ fell $\left(\triangle F E_{A I B}\right.$, $-0.035 \pm 0.007$ after $30 \mathrm{~min} ; P<0.01), F_{P}$ increased after 60 $\min \left(\Delta \mathrm{FE}_{\mathrm{P}},+0.017 \pm 0.01 ; P<0.001\right)$, and GFR fell $(\Delta \mathrm{GFR}$, $-0.125 \pm 0.04$ after $30 \mathrm{~min} ; P<0.01$ ). The change in phosphaturia
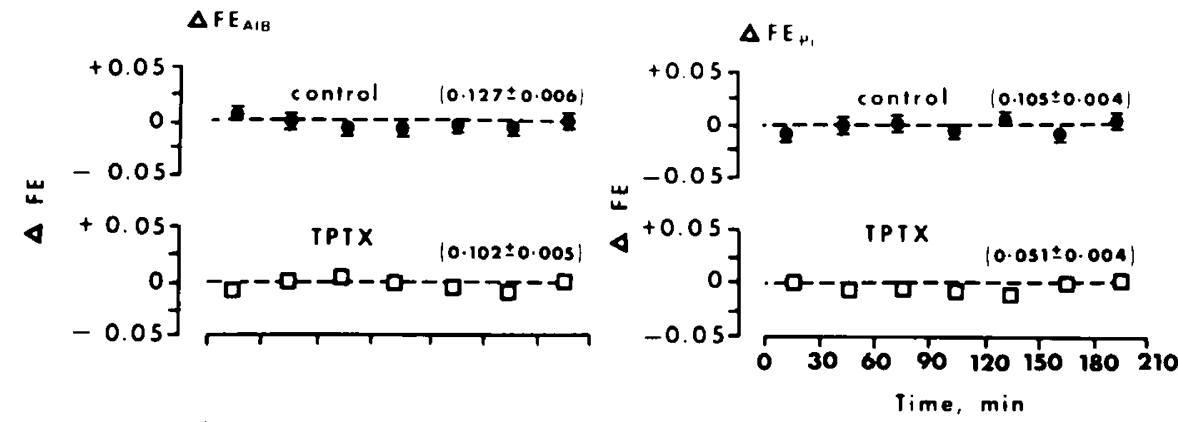

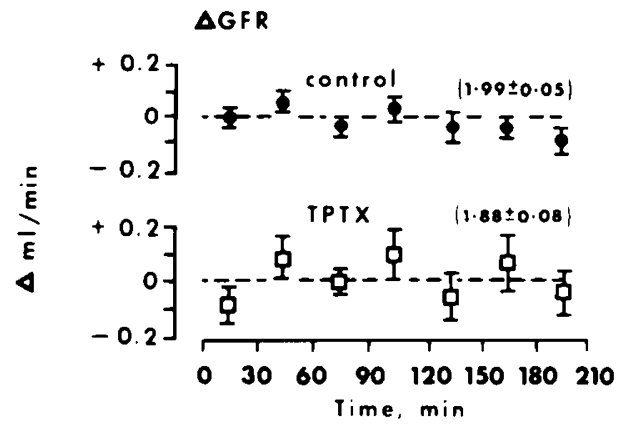

Fig. 1. The change in fractional excretion of the inert amino acid $A I B$ and phosphate anion $\left(\Delta F E_{A l B}\right.$ and $\left.\triangle F E_{P_{i}}\right)$, and change in inulin clearance $(\Delta G F R)$ as a function of time in intact $(n=10)$ and TPTX $(n=10)$ rats. Data are presented as the average + S.E. of the difference between the mean of the first three clearance periods and each individual period for the individual rats. Interindividual differences between animals are thus accommodated. Numbers above each set of data are mean \pm S.E. of absolute values for the group in periods one through three. 

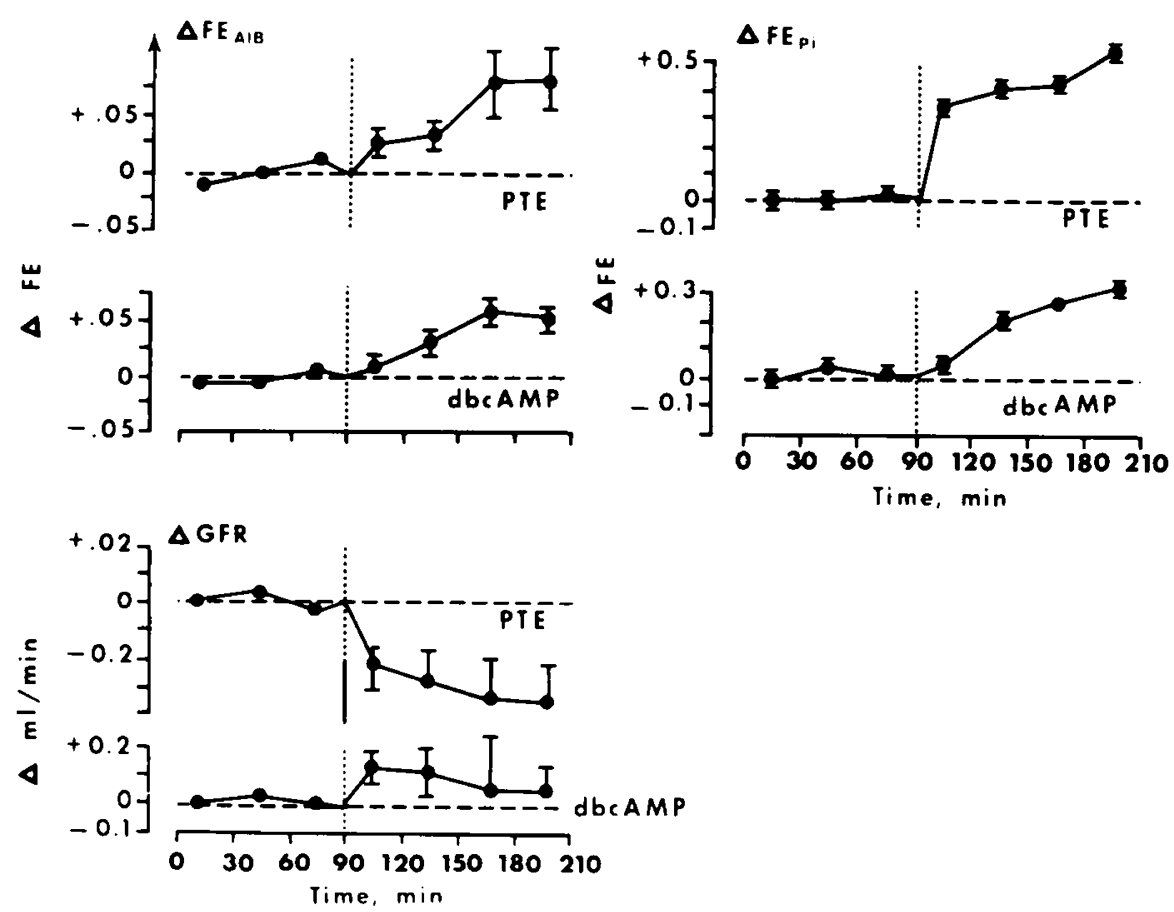

Fig. 2. $\triangle F E_{A I B}, \triangle F E_{p}$, and $\triangle G F R$ as a functon of time in the intact rat, infused with PTE $(n=8)$ or dbcAMP $(n=6)$. Data are presented as the difference (mean \pm S.E.) between the mean of the first three (control) periods (- - - ) and each individual period (for both control or treatment clearance periods). Treatments (PTE or dbcAMP) began at $90 \mathrm{~min}$ and continued throughout periods 4 to 7 (90 to $120 \mathrm{~min}$ ); the vertical broken line indicates onset of treatment.
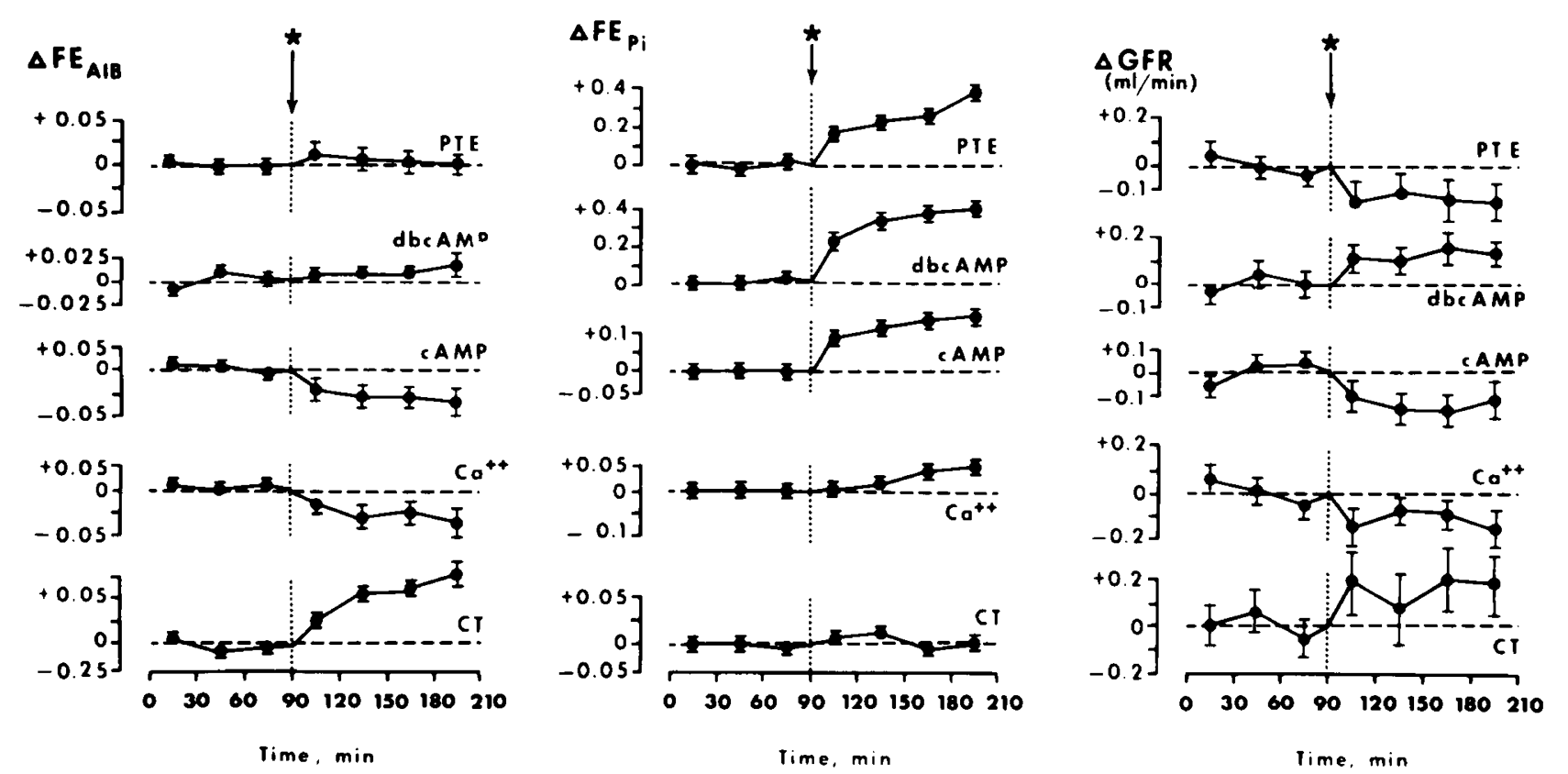

Fig. 3. $\triangle F E_{A I B}, \triangle F E_{P,}$, and $\triangle G F R$ as a function of time in the TPTX rat group. Calciotropic agents and $\mathrm{CaCl}_{2}$ were administered, and their effect was measured as explained in Figure 2. Number of animals in each group shown in Table 1.

could be attributed to known effects of concurrent hypercalcemia on phosphate metabolism (13).

\section{RESPONSE TO CALCITONIN INFUSION: TPTX RAT}

CT increased AIB excretion significantly $\left(\triangle \mathrm{FE}_{\mathrm{AIB}},+0.064 \pm\right.$ 0.005 after $30 \mathrm{~min} ; P<0.001$ ), but it had no effect on $F E_{P}$ in the TPTX rat (Fig. 3). CT produced fluctuations in GFR, but this response was limited to two rats given 500 munits $/ \mathrm{kg} \cdot \mathrm{hr}$. In 5 rats given 25 munits $/ \mathrm{kg} \cdot \mathrm{hr}$, the control GFR was $2.04 \pm 0.06 \mathrm{ml} / \mathrm{min}$ (mean \pm S.E.; $n=15$ ), and it did not change with CT infusion (2.06 $\pm 0.08 \mu \mathrm{l} / \mathrm{min}$, mean \pm S.E.; $n=20$ ) during CT infusion; these five animals showed the aforementioned responses in $\mathrm{FE}_{\mathrm{AIB}}$ and $F E_{P}$.

\section{EFFECT OF CYCLIC NUCLEOTIDES AND HORMONES ON:}

Plasma Calcium. The plasma level of calcium was stable in the intact and TPTX rat (Table 1). TPTX reduced plasma total calcium $(P<0.001)$, as expected. Infusion of PTE and dbcAMP into the intact rat had no effect on total plasma calcium; in the TPTX rat, PTE, cAMP, and $\mathrm{CaCl}_{2}$ raised it significantly (see Table 1 for $P$ values), dbcAMP had no effect, and CT lowered it $(P<0.001)$. 
Plasma Phosphate. The plasma level of phosphate was stable in the intact and TPTX rat (Table 2). TPTX increased plasma phosphate $(P<0.001)$. The anticipated fall in plasma phosphate was observed following infusion of PTE and dbcAMP in both the intact and TPTX rat $(P<0.001)$. CAMP and CT reduced plasma phosphate $(P<0.001)$ in the TPTX rat, while $\mathrm{CaCl}_{2}$ had no effect.
Plasma [AIB] and Filtered Load of AIB. Plasma [AIB] was stable in the intact and TPTX rat under control conditions (Fig. 4). Infusions of dbcAMP and CT into the intact and TPTX rat were each followed by significant changes in plasma [AIB]. The fall in plasma [AIB] following dbcAMP infusion in the intact rat $(P<0.001)$ (Fig. 4) was accompanied by a reciprocal increase in

Table 1. Effect of hormones and nucleotides on plasma calcium (mg/dl)

\begin{tabular}{|c|c|c|c|c|c|c|c|c|c|}
\hline \multirow[b]{2}{*}{ Period } & \multicolumn{2}{|c|}{ Control } & \multicolumn{2}{|c|}{ dbcAMP } & \multicolumn{2}{|c|}{ PTE } & \multirow{2}{*}{$\begin{array}{c}\text { CT } \\
\text { TPTX }\end{array}$} & \multirow{2}{*}{$\begin{array}{l}\text { cAMP } \\
\text { TPTX }\end{array}$} & \multirow{2}{*}{$\begin{array}{l}\mathrm{CaCl}_{2} \\
\text { TPTX }\end{array}$} \\
\hline & Intact & TPTX & Intact & TPTX & Intact & TPTX & & & \\
\hline \multicolumn{10}{|l|}{ Preinfusion } \\
\hline 1 & $9.6 \pm 0.2^{\prime}$ & $7.7 \pm 0.2$ & $10.0 \pm 0.2$ & $6.9 \pm 0.4$ & $9.0 \pm 0.3$ & $7.1 \pm 0.3$ & $7.3 \pm 0.3$ & $7.9 \pm 0.2$ & $8.2 \pm 0.4$ \\
\hline 3 & $9.9 \pm 0.3$ & $7.4 \pm 0.3$ & $10.0 \pm 0.3$ & $7.7 \pm 0.4$ & $9.2 \pm 0.4$ & $6.9 \pm 0.4$ & $7.2 \pm 0.4$ & $7.7 \pm 0.3$ & $8.2 \pm 0.4$ \\
\hline \multicolumn{10}{|l|}{ Postinfusion $^{2}$} \\
\hline 5 & $9.8 \pm 0.3$ & $7.4 \pm 0.3$ & $9.8 \pm 0.3$ & $7.7 \pm 0.3$ & $9.2 \pm 0.5$ & $7.5 \pm 0.4$ & $6.2 \pm 0.3$ & $8.4 \pm 0.3$ & $9.9 \pm 0.4$ \\
\hline 7 & $10.0 \pm 0.4$ & $7.3 \pm 0.3$ & $9.8 \pm 0.4$ & $7.4 \pm 0.4$ & $8.9 \pm 0.3$ & $9.4 \pm 0.6$ & $5.8 \pm 0.3$ & $9.2 \pm 0.5$ & $11.9 \pm 0.2$ \\
\hline $\mathrm{n}$ & 10 & 10 & 6 & 8 & 8 & 10 & 7 & 7 & 7 \\
\hline \multicolumn{10}{|c|}{ Significance of change } \\
\hline & n.s. ${ }^{4}$ & n.s. & n.s. & n.s. & n.s. & $P<0.005$ & $P<0.001$ & $P<0.01$ & $P<0.001$ \\
\hline
\end{tabular}

${ }^{1}$ Mean \pm S.E.

${ }^{2}$ No infusion was given to rats reported in first two columns.

${ }^{3}$ Tests of significance were determined by analysis of variance (48) for preinfusion periods versus postinfusion periods.

4 n.s., not significant.

Table 2. Effect of hormones and nucleotides on plasma phosphate $(\mathrm{mg} / \mathrm{dl})$

\begin{tabular}{|c|c|c|c|c|c|c|c|c|c|}
\hline \multirow[b]{2}{*}{ Period } & \multicolumn{2}{|c|}{ Control } & \multicolumn{2}{|c|}{ dbcAMP } & \multicolumn{2}{|c|}{ PTE } & \multirow{2}{*}{$\begin{array}{c}\text { CT } \\
\text { TPTX }\end{array}$} & \multirow{2}{*}{$\begin{array}{l}\text { cAMP } \\
\text { TPTX }\end{array}$} & \multirow{2}{*}{$\begin{array}{l}\mathrm{CaCl}_{2} \\
\text { TPTX }\end{array}$} \\
\hline & Intact & TPTX & Intact & TPTX & Intact & TPTX & & & \\
\hline \multicolumn{10}{|l|}{ Preinfusion } \\
\hline 1 & $5.7 \pm 0.2^{1}$ & $8.5 \pm 0.3$ & $6.2 \pm 0.4$ & $9.1 \pm 0.7$ & $5.7 \pm 0.3$ & $8.5 \pm 0.2$ & $7.9 \pm 0.3$ & $9.1 \pm 0.4$ & $8.3 \pm 0.21$ \\
\hline 2 & $5.8 \pm 0.2$ & $8.9 \pm 0.2$ & & $9.1 \pm 0.7$ & $5.8 \pm 0.3$ & & $8.1 \pm 0.3$ & $8.8 \pm 0.4$ & \\
\hline 3 & $5.8 \pm 0.2$ & $8.6 \pm 0.2$ & $6.0 \pm 0.3$ & $8.7 \pm 0.7$ & $5.8 \pm 0.3$ & $8.5 \pm 0.3$ & $7.9 \pm 0.3$ & $8.5 \pm 0.3$ & $8.2 \pm 0.4$ \\
\hline \multicolumn{10}{|l|}{ Postinfusion ${ }^{2}$} \\
\hline 4 & $5.9 \pm 0.2$ & $8.5 \pm 0.1$ & & $7.9 \pm 0.3$ & $4.9 \pm 0.3$ & & $7.1 \pm 0.2$ & $7.9 \pm 0.4$ & \\
\hline 5 & $5.8 \pm 0.2$ & $8.5 \pm 0.2$ & $5.1 \pm 0.3$ & $6.3 \pm 0.4$ & $4.3 \pm 0.3$ & $6.9 \pm 0.3$ & $6.7 \pm 0.2$ & $7.1 \pm 0.5$ & $8.6 \pm 0.3$ \\
\hline 6 & $5.9 \pm 0.2$ & $8.5 \pm 0.1$ & & $5.9 \pm 0.4$ & $4.2 \pm 0.2$ & & $6.4 \pm 0.2$ & $6.7 \pm 0.5$ & \\
\hline 7 & $5.8 \pm 0.2$ & $8.2 \pm 0.2$ & $4.3 \pm 0.2$ & $5.9 \pm 0.4$ & $3.9 \pm 0.2$ & $6.0 \pm 0.3$ & $6.3 \pm 0.2$ & $6.1 \pm 0.3$ & $8.6 \pm 0.2$ \\
\hline $\begin{array}{l}\text { Statistical } \\
\quad \text { significance }\end{array}$ & n.s. & n.s. & $P<0.001$ & $P<0.001$ & $P<0.001$ & $P<0.001$ & $P<0.001$ & $P<0.001$ & n.s. \\
\hline
\end{tabular}

${ }^{1}$ Mean \pm S.E.

${ }^{2}$ No infusion was given to rats reported in first two columns.

${ }^{3}$ Tests of significance were determined by analysis of variance (48) for preinfusion periods versus postinfusion periods.

4 n.s., not significant.
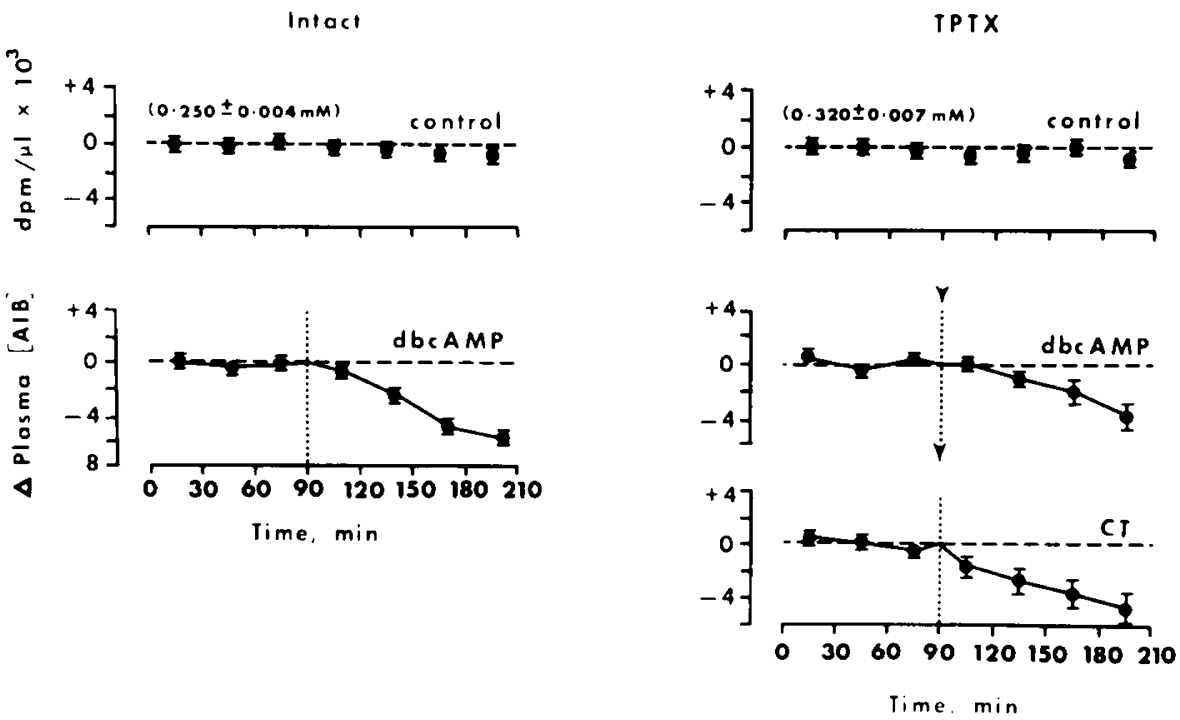

Fig. 4. Change in plasma [AIB] ( $\Delta$ plasma [AIB]) as a function of time in the intact and TPTX rat under control conditions and after infusion of dbcAMP and CT, and their effect measured as explained in Figure 2. Number of animals in each group shown in Table 1. 
$F E_{\text {AIB }}$ (Fig. 2); the latter was not accounted for by significant net change in filtered load because GFR increased during the abovementioned changes in plasma $[A I B]$ and $F_{A}$ AIB. Despite a similar fall in plasma [AIB] $(P<0.001)$ in the TPTX rat following dbcAMP infusion (Fig. 4), and a similar increase in GFR (Fig. 3), $F E_{A I B}$ did not increase. On the other hand, CT both decreased

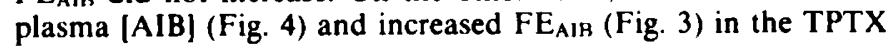
rat.

\section{DISCUSSION}

PTE increased renal excretion of AIB in the intact, vitamin Dreplete animal in our study. Micropuncture in the intact rat was used previously by Gekle (19) to confirm that PTH will decrease net reabsorption of natural amino acids in situ. These findings seem to support the hypothesis that the hyperaminoaciduria associated with deficiency of vitamin $D(17)$ or calcium $(28,33)$ in both man and the rat (23) is caused by the hyperparathyroidism that occurs with these hypocalcemic conditions. However, other forms of hyperparathyroidism in man are not uniformly associated with impaired renal reabsorption of amino acids $(14,39,48)$. An explanation for the irregular effect of PTH on tubular reabsorption of amino acids and for its mechanism of action in causing hyperaminoaciduria is offered by the study reported here.

The failure to increase renal excretion of AIB following infusions of PTE and dbcAMP in the TPTX rat is the key observation in our investigation. Because prolongation of the PTE infusion up to $12 \mathrm{hr}$ in the TPTX rat, and EGTA infusion sufficient to cause hyperparathyroidism in the intact animal (35) both failed to elicit hyperaminoaciduria, we must conclude that hyperparathyroidism by itself is an insufficient condition for impaired tubular reabsorption of amino acids.

A permissive effect of the thyroid gland on the genesis of hyperaminoaciduria following infusions of PTE and dbcAMP is indicated. Increased secretion of either thyroxin or calcitonin could be involved. PTH itself is not expected to alter thyroid hormone secretion. Although secretion of thyroid hormone is an adenyl cyclase-dependent mechanism, which can be stimulated by dibutyryl cAMP (16), the rapid change in AIB excretion following dbcAMP is inconsistent with the characteristically slow response of cellular events to the hormone (22). Furthermore, hyperthyroidism is not known to cause hyperaminoaciduria (47).

Increased secretion of calcitonin follows exposure of the thyroid gland to the dbcAMP, both in vitro (4) and in vivo (8). Although PTH does not stimulate calcitonin secretion directly, its hypercalcemic effect is a potent stimulus for CT release experimentally (43). Persistence of normocalcemia in the PTE-infused intact animal is evidence that calcitonin released by the thyroid gland, could have been significant in our experiments; plasma calcium was increased by PTE only in the TPTX rat in our experiments.

Calcitonin promptly increased AIB excretion in the TPTX rat. We observed a similar effect in the single intact animal that we studied (35). The small but significant decrease in baseline FE $F_{\text {AlR }}$ in the TPTX rat is also consistent with an effect of CT in vivo at physiologic concentrations. Small infusions of CT ( 25 munits $/ \mathrm{kg}$. $\mathrm{hr}$ ) did not alter GFR or urine flow rate while $F E_{\text {AIB }}$ was increasing. Other workers (42) have shown that CT does not alter renal plasma flow. Thus, there is no evidence that the increase in AIB excretion induced by $\mathrm{CT}$ is secondary to altered renal hemodynamics.

The lack of a phosphaturic effect following $\mathrm{CT}$ infusion in our TPTX (and intact) rats concurs with some studies (50), but conflicts with others (41). The reasons for these varying results are unclear (2), but some of the differences may be dose related, an impression supported by Robinson et al. (45). For example, although the effect on amino acid excretion in our studies was obtained with 25 munits/ $\mathrm{kg} \cdot \mathrm{hr}$ of porcine $\mathrm{Ct}$, the dose used to achieve phosphaturia with the more potent salmon in other experimental (41) was $\sim 3200$-fold larger. We suggest that induction of phosphaturia may be a pharmacologic rather than a physiologic action of CT.

It is not known whether the renal effects of CT are mediated by
cAMP. CT-responsive adenyl cyclase activity has been identified largely in the medullary and cortical portions of the thick ascending limb and in the distal convoluted tubule (9). Whether these regions of the nephron could be the sites of decreased AIB uptake from the lumen or of an increased cell-to-lumen flux of AIB (36) remains to be determined.

Borle (6) suggests that a major effect of CT is to lower the cytoplasmic calcium ion concentration. A depression of cytoplasmic calcium has been found in renal cells of vitamin D-deficient chicks (7). A role for cytoplasmic calcium in the control of membrane permeability has been recognized in other tissues $(7$, 34. 44). Increased permeability to ions and other solutes follows elevation of cytoplasmic calcium $(3,21,29,46)$. Consequently, a depression of renal cytoplasmic calcium might decrease permeability of the brush border membrane. thereby impairing net reabsorption of amino acids. Therefore, depletion of cell calcium stores, with a fall in cytoplasmic calcium ion and membrane permeability, might be the common denominator underlying the tubular dysfunction in calcium deficiency, vitamin $D$ deficiency, and isolated deficiency of 1,25-dihydroxycholecalciferol (15). We can speculate further that decreased cytoplasmic calcium ion might occur in some target organs in primary hyperparathyroidism because of increased calcitonin release $(24)$ and relative deficiency of vitamin D hormone $(32,54)$.

There is some evidence that alterations in renal hemodynamics may play a role in the tubulopathy of primary and secondary hyperparathyroidism (37). This is a particular problem when PTE is used instead of PTH, as was the case in our studies. Perturbation of renal hemodynamics by PTE was indicated by the fall in GFR and urine flow rate in our intact and TPTX rats. However, it is unlikely that these changes are responsible for increased $F_{A}$ AIB in the intact PTE-infused rat because $F E_{A I B}$ in TPTX rats was unaffected by PTE, despite changes in GFR and flow rate analogous to those found in intact animals. With dbcAMP infusion, an increase in GFR and urine flow rate occurred in the intact and TPTX animal, yet AIB excretion still increased in the intact group. Thus, while PTE and dibutyryl cAMP both increase $F_{A 1 B}$ in intact rats, they have divergent effects on GFR.

Further evidence against a simple relationship between GFR and $\mathrm{FE}_{\mathrm{AIB}}$, in response to calciotropic agents, is found in our studies with cAMP and $\mathrm{CaCl}_{2}$. Decreased renal blood flow and GFR in response to cAMP has been described previously $(20,27)$. Although the fall in GFR induced by calcium may be PTH dependent (25), we still observed this response in TPTX rats. Because GFR decreased in situations in which $F E_{\text {AIB }}$ either fell (calcium and cAMP infusions in TPTX rats), remained unchanged (PTE infusion in TPTX rats), or rose (PTE infusion in the intact rat), or GFR increased in situations in which $F_{\text {AIB }}$ either rose (dibutyryl cAMP infusion in the intact rat) or remained unchanged (dbcAMP infusion in TPTX rats), we must conclude that hemodynamic changes are an insufficient explanation for the changes in $\mathrm{FE}_{\mathrm{AIB}}$ in response to calciotropic agents.

It is probable that the alterations in GFR induced by PTE are not the effect of parathyroid hormone itself but rather of contaminants in the extract (2). Dibutyryl cAMP has been reported to be without effect on the renal vasculature of the dog (20), but other studies suggest that it has vasodilatory actions $(5,27)$ which could be consistent with the effects we observed.

Finally, there is a particular effect of dbcAMP to be considered. Plasma [AIB] fell in the intact and TPTX rat treated with the nucleotide. This change cannot be related to increased urinary loss of AIB alone, although the rapid decrease in plasma [AIB] in the intact rat may reflect the increased renal excretion of amino acid. Enhanced AIB uptake by liver and other organs $(10,39,53)$ is probably an important cause for the fall in plasma [AIB] following treatment with dbcAMP. However, this analog depletes kidney of AIB in situ (18), a decrease which could reflect increased flux of AIB from cells to lumen (36).

\section{CONCLUSION}

Hyperparathyroidism has been proposed as an essential cause of hyperaminoaciduria and hyperphosphaturia in vitamin D de- 
ficiency and dietary hypocalcemia. However, primary hyperparathyroidism is not uniformly accompanied by hyperaminoaciduria This discrepancy has been investigated further in a rat model using the inert amino acid AIB as a probe of amino acid reabsorption in vivo. We observed that PTE and dbcAMP increased $F E_{A I B}$ and $F E_{P i}$ in the intact, sham-operated rat whereas neither agent increased $F_{A I B}$ in the TPTX animal. In the latter, small doses of $C T$ ( 25 munits $/ \mathrm{kg} \cdot \mathrm{hr}$ ) increased $F E_{\mathrm{AIB}}$ significantly without change in $\mathrm{FE}_{\mathrm{Pi}}$. These findings indicate different mechanisms for hyperaminoaciduria and hyperphosphaturia in response to calciotropic agents. We propose that net reabsorption of amino acids in hyperparathyroid states is modulated by CT, perhaps through its effect on cytosol calcium and membrane permeability of renal tubular epithelium.

\section{REFERENCES AND NOTES}

1. Arnaud. C.. Glorieux. F.. and Scriver, C. R.: Serum parathyroid hormone levels in acquired vitamin D deficiency or infancy. Pediatrics, 49: 837 (1972).

2. Aurbach. G. D., and Heath D. A.: Parathyroid hormone and calcitonin regulation of renal function. Kidney Int. 6: 33 I (1974).

3. Baker, P. F.: Transport and metabolism of calcium ions in nerve. In: J. A. V. Butler. D. Noble: Progress in Biophysics and Molecular Biology. Vol. 24, p 179 (Pergamon Press. New York, 1972).

4. Bell. N. H and Queener. $\mathrm{S}$.: Stimulation of calcitonin synthesis and release in vitro by calcium and dibutyryl cyclic AMP. Nature (Lond.). 248: 343 (1974).

5. Berti. F.. Bernareggi. V.. and Mandelli. V.: Contraction and relaxation of in vitro perfused rat caudal anery: a possible role for cyclic 3'5'-AMP. Arch. Int.. Pharmacodyn. Ther.. 192: 247 (1971).

6. Borle. A B. Calcium metabolism at the cellular level. Fed. Proc. 32: 1944 (1973).

7. Borle. A. B.: Kinetic studies of calcium movements in intestinal cells: effects of vitamin D deficiency and treatment. J. Membr. Biol.. 10: 207 (1974).

8. Care. A. D., Bates. R. F. L., and Gitelman. H. J.: A possible role for the adenyl cyclase system in calcitonin release. J. Endocrinol.. 48: I (1970),

9. Chabardes, D.. Imbert-Teboul, M.. Montegut. M., Clique. A., and Morel. F.: Distribution of calcitonin-sensitive adenyl cyclase activity along the rabbit kidney tubule. Proc. Natl. Acad. Sci. U. S. A.. 7.3: 3608 (1976).

10. Chambert. J. W.. Georg. R. H., and Bass. A. D.: Effect of glucagon, cyclic 3'5'adenosine monophosphate and its dibutyryl derivative on amino acid uptake by the isolated perfused rat liver. Endocrinology. 87: 366 (1970).

11. Chase, L. R.. and Aurbach. G. D.: Parathyroid function and renal excretion of 3'. 5'-adenylic acid. Proc. Natl. Acad. Sci. U. S. A. 58: 518 (1967).

12. Chesney. R. W.. and Harrison. H. E.: Fanconi syndrome following bowel surgery and hepatitis reversed by 25 -hydroxycholecalciferol. J. Pediatr.. 86: 857 (1975).

13. Cuche. J. L.. Ott. C. E.. Marchand. G. R.. Diaz-Buxo, J. A., and Knox. F. G.: Intrarenal calcium in phosphate handling. Am. J. Physiol., 230: 790 (1976).

14. Cusworth. D. C.. Dent, C. E., and Scriver, C. R.: Primary hyperparathyroidism and hyperaminoaciduria. Clin. Chim. Acta. 4l: 355 (1972).

15. Drezner. M. K., and Feinglos. M. N.: Osteomalacia due to $1 \alpha .25$-dihydroxycholecalciferol deficiency. J. Clin. Invest.. 60: 1046 (1977).

16. Dumont. J. E.: The action of thyrotropin on thyroid metabolism. Vitam. Horm. 29: $287(1971)$

17. Fraser, D., Kooh. S. W.. and Scriver, C. R.: Hyperparathyroidism as the cause of hyperaminoaciduria and phosphaturia in human vitamin $D$ deficiency. Pediatr. Res., I: 425 (1967).

18. Fuller. R. W., and Baker. J. C.: Effect of glucagon and dibutyryl cyclic AMP on the tissue distribution of $\left[{ }^{14} \mathrm{C}\right] \alpha$-aminoisobutyric acid in rats. FEBS Lelt., 53 : $8(1975)$.

19. Gekle. D.: The influence of parathyroid hormone on renal function. Pflugers Arch. Eur. J. Physiol.. 323: 96 (1971).

20. Gill. J. R.. Casper. A. G. T.. and Tate. J.: Renal effects of adenosine 3'.5'-cyclic monophosphate and dibutyryl adenosine $3^{\prime}, 5^{\prime}$-monophosphate. J. Clin. Invest. 50: 1231 (1971).

21. Godfraind, J. M. Kawamura. H.. Krnjevic. K., and Pumain. P.: Action of dinitrophenol and some other metabolic inhibitors on cortical neurons. J. Physiol. (Lond.). 215: 199 (1971)

22. Gordon. P.. Robbins, J., and Rall. J. E.: The thyroid and iodine metabolism. In P. K. Bondy, L. E. Rosenberg: Duncan's Diseases of Metabolism. 7th ed. Chap. 17. (W. B. Saunders. Philadelphia, 1974)

23. Grose. J. H., and Scriver, C. R.: Parathyroid-dependent phosphaturia and aminoaciduria in the vitamin D-deficient rat. Am. J. Physiol., 214: 370 (1968),

24. Heynen. G.. and Franchimont. P.: Human calcitonin radioimmunoassay in normal and pathological conditions. Eur. J. Clin. Invest., 4: 213 (1974).

25. Humes. H. D.. Ichikawa. I.. Troy. J. L., and Brenner. B. M.: Evidence for a parathyroid hormone-dependent influence of calcium on the glomerular ultrafiltration coefficient. J. Clin. Invest., 61: 32 (1978).

26. Joffe, B. I. Hackens, W. H. L., Seftel, H. C.. and Hartdegen, R. G.: Parathyroid hormone concentrations in nutritional rickets. Clin. Sci. (Oxf.), 42: 113 (1972).
27. Kokubun. H.: Direct effects of cyclic AMP and dibutyryl cyclic AMP on renal blood flow. Tohoku S. Exp. Med.. 116: 295 (1975).

28. Kooh. S. W.. Fraser. D., Reilly. B. J., Hamilton. J. R., Gall. D. G., and Bell. L.: Rickets due to calcium deficiency. N. Engl. J. Med., 297: 1264 (1977).

29. Lew. V. L.: Effect of intracellular calcium on the potassium permeability of human red cells. J. Physiol. (Lond.), 206: 35 (1970).

30. Lorentz, W. B.: The effect of cyclic AMP and dibutyryl cyclic AMP on the permeability characteristics of the renal tubule. J. Clin. Invest.. S3: 1250 (1974).

31. Lorentz. W. B.: Effect of parathyroid hormone on renal tubular permeability. Am. J. Physiol., 231: 1401 (1976).

32. Lumb. G. A., and Stanbury. S. W.: Parathyroid function in human vitamin D deficiency and vitamin $D$ deficiency in primary hyperparathyroidism. Am. J. Med., 56: 833 (1974).

33. Maltz. H. E.. Fish, M. B., and Holliday, M. A.: Calcium deficiency rickets and the renal response to calcium infusion. Pediatrics, 46: $865(1970)$.

34. Manery, J. F.: Effects of calcium ions on membranes. Fed. Proc., 25: 1804 (1966)

35. R. R. McInnes, unpublished observations.

36. Mclnnes. R. R., and Scriver, C. R.: Net reabsorption of $\alpha$-aminoisobutyric acid by rat kidney in vivo. Am. J. Physiol., 237: F274 (1979).

37. Morris, R. C.. Mclnnes, R. R.. Epstein, C. J.. Sebastian, A., and Scriver, C. R. In: B. M. Brenner, F. C. Rector: The Kidney. Chap. 27, p. 1204 (W. B. Saunders. Philadelphia. 1976).

38. Morris. R. C.. Sebastian, A., and McSherry, E.: Renal acidosis. Kidney Int., I: 322 (1972)

39. Muldowney. F.. P.. Freaney. R.. and McGeeney. D.: Renal tubular acidosis and aminoaciduria in osteomalacia of dietary or intestinal origin. Q. J. Med., 37. $517(1968)$

40. Phang. J. M.. and Downing. S. J.: Amino acid transport in bone: stimulation by cyclic AMP. Am. J. Physiol., 224: 191 (1973).

41. Popovtzer, M. M., Blum. M. S., and Flis, R. S.: Evidence for interference of 25 (OH) vitamin $D_{\text {; }}$ with phosphaturic action of calcitonin. Am. J. Physiol., 232 ESIS (1977).

42. Puschelt. J. B., Beck, W. S., Jr., Jelonek, A., and Fernandez, P. C.: Study of the renal tubular interactions of thyrocalcitonin, cyclic adenosine $3^{\prime}, 5^{\prime}$-monophosphate. 25-hydroxycholecalciferol, and calcium ion. J. Clin. Invest.. 53: 756 (1974).

43. Queener. S. F., and Bell. N. H.: Calcitonin: A general survey. Metabolism. 24 555 (1975)

44. Rasmussen. H.. and Bordier. P.: The Physiological and Cellular Basis of Metabolic Bone Disease. Chap. 4. p. 105 (Williams \& Wilkins Co., Baltimore. 1974)

45. Robinson. C. J., Martin, T. J., and MacIntyre, I.: Phosphaturic effect of thyrocalcitonin. Lancet. 2: 83 (1966).

46. Romero. P. J., and Whittam. R.: The control by internal calcium of membrane permeability to sodium and potassium. J. Physiol. (Lond.), 214: 481 (1971).

47. Scriver. C. R.. and Rosenberg. L. E.: Amino Acid Metabolism and its Disorders. (W. B. Saunders. Philadelphia. 1973).

48. Short. E. M.. Elsas. L. J., and Rosenberg. L. E.: Effect of parathyroid hormone on renal tubular reabsorption of amino acids. Metabolism. 23: 715 (1974).

49. Sokal, R. R., and Rohlf, F. J.: Biometry. (W. H. Freeman and Co., San Francisco, 1969).

50. Sorensen. O. H., and Hindberg. l.: The acute and prolonged effect of porcine calcitonin on urine electrolyte and excretion in intact and parathyroidectomized rats. Acta Endocrinol., 70: 295 (1972).

51. Sovik, O., Aksnes, L., and Apold. J.: Urinary cyclic AMP: high concentrations in vitamin D-deficient and -dependent rickets. J. Pediatr. 89: 946 (1976).

52. Vainsel. M.. Manderlier. T.. and Otten. J.: Urinary excretion of adenosine $3^{\prime}, 5^{\prime}$. monophosphate in vitamin D deficiency. Eur. J. Clin. Invest., 6: 127 (1976)

53. Weiss. I. W. Morgan. K. and Phang, J. M. Cyclic adenosine monophosphate stimulated transport of amino acids in kidney cortex. J. Biol. Chem., 247: 760 (1972).

54. Woodhouse. N. S. Y., Doyle, F. H., and Joplin. G. F.: Vitamin-D deficiency and primary hyperparathyroidism. Lancet, 2: 283 (1971).

55. Presented in preliminary form at the Fifth Parathyroid Conference, Oxford United Kingdom, July 21-26, 1974. Namely, Scriver, C. R., Mclnnes, R. Tenenhouse. H.. Reade. T.. and Glorieux. F. H. The further delineation of acquired vitamin $D$ deficiency, autosomal recessive vitamin $D$ dependency and X-linked hypophosphatemia. In R. V. Talmage. M. Owen, J. A. Parsons: Calcium Regulating Hormones, pp. 421-430. (Excerpta Medica ICS 346, Amsterdam 1975).

56. The present address of Dr. Roderick R. Mclnnes is: The Hospital for Sick Children Research Institute. 555 University Avenue. Toronto, Ontario, Canada MSG 1X8.

57. The authors thank Fazl Mohyuddin and John Seeley for helpful discussions and advice.

58. Requests for reprints should be addressed to: Dr. Charles R. Scriver, M.D., The De Belle Laboratory for Biochemical Genetics. Montreal Children's Hospital Research Institute, 2300 Tupper Street. Montreal. Quebec, Canada H3H IP3. 59. This research was supported by the Medical Research Council of Canada and by a Fellowship to Dr. Mclnnes from the Cystic Fibrosis Foundation of Canada.

60. Received for publication February 12, 1979.

61. Accepted for publication April 26, 1979 